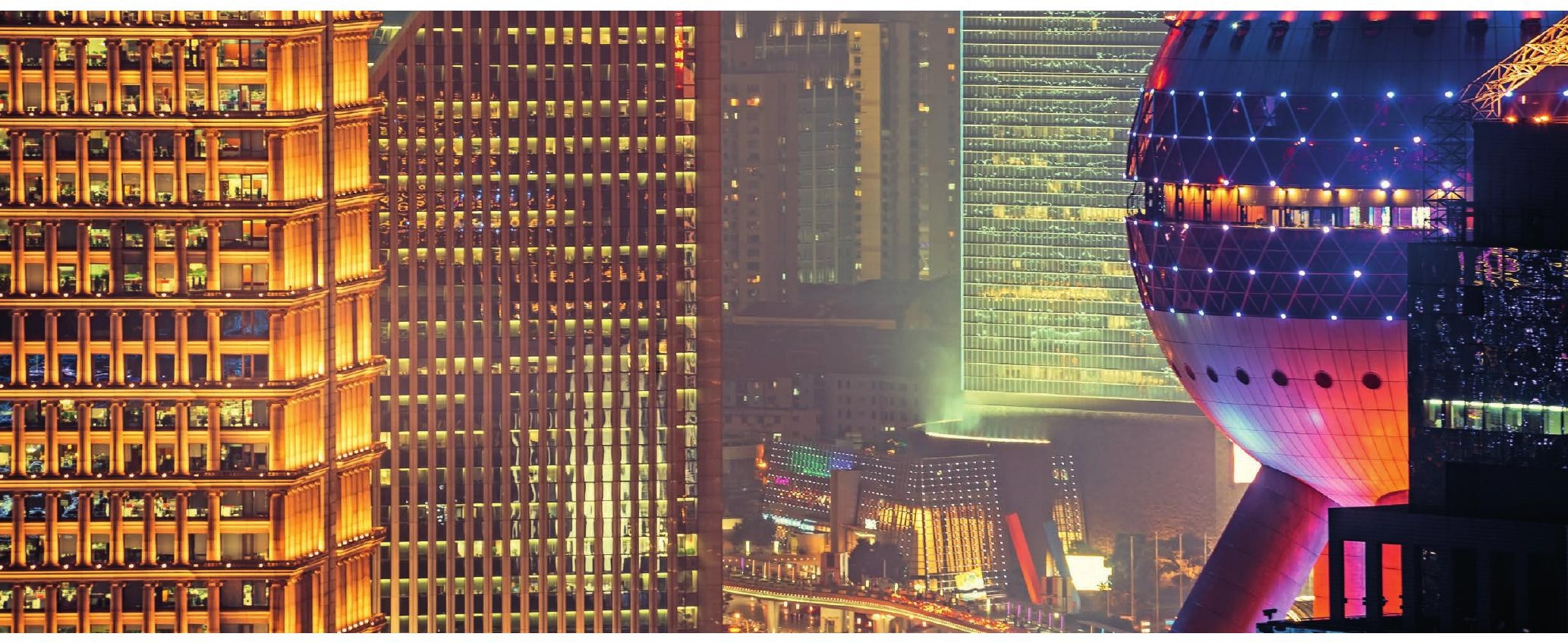

\title{
METROPOLIS OF MINDS
}

S cience is an urban enterprise. In 2016, some $60 \%$ of the share of authorship in the Nature Index came from 100 cities. The top 10 metropolises accounted for $17 \%$ of the total research output, which is 17 times their global population weight. With two-thirds of the world's population projected to live in urban areas by 2050, cities will become even more distinctly the domain of knowledge and innovation.

This supplement explores the high-quality research in the natural sciences being produced by 10 cities, chosen for their strong scientific credentials, metropolitan flair and global connections.

While they have many common features, each metropolis also has unique strengths. Research institutions in London have been at the forefront of learning for almost two centuries, which puts them in a strong position to resist any Brexitrelated disruptions (S164). On the other side of the Atlantic, New York is in the early stages of refashioning itself into a biotech hub, but it might need more than a strong life sciences base and deep pockets (S168).

Cities don't exist in isolation. They form regional and global networks that facilitate the movement of money, people and ideas. The line between collaboration and competition is often fine. Daejeon, for example, has become a focus for basic science in South Korea: 19\% of its GDP is spent on research and development, compared to Seoul's 3\%, and 2\% of Daejeon's population are researchers, double the share in Seoul (S176). Daejeon's output has held firm despite a drop of almost $20 \%$ over the past five years in Seoul, coinciding with a national decline. Other city pairs face a similar tug-of-war: Barcelona and Madrid, Shenzhen and Guangzhou, Shanghai and Beijing.

Ease of movement between urban centres makes cities vulnerable to their rivals, but it is also their greatest asset. This competitive edge, however, is under threat from populist campaigns that seek to block the free-flow of people and curtail investment in science, argues Richard Florida on page S172. When the barricades go up, it won't take long for scientists to move on to the next big metropolis.

The research performance of a city is always in flux, and the combination of factors that make a successful science city is not firmly characterized. Better definition through research and analysis will provide cities stronger defence against ill-informed attack.

\section{Smriti Mallapaty}

Senior editor, Nature Index
EDITORIAL: Catherine Armitage, Smriti Mallapaty, Stephen Pincock, Nicky Phillips, Rebecca Dargie, Herb Brody, Victoria Kitchener ANALYSIS: Aaron Ballagh, Bo Wu ART \& DESIGN: Alisdair Macdonald, Daniel Ormella, Kate Duncan, Mohamed Ashour, Ruffi Lu, Chika Takeda, Wojtek Urbanek WEB DEVELOPMENT \& DESIGN: Bob Edenbach, Olivier Lechevalier, Naom Nakahara, Pamela Sia, Bart Riepe DATA QUALITY: Jörn Ishikawa, Yuxin Wang, Paul Glaeser, Jennie Pao, Alexander Scherrmann, Randell Roach, Miho Kawana, Megha Katyal PRODUCTION: Sue Gray, Karl Smart, lan Pope, Matt Carey, Ali Mosud MARKETING: Stacy Best Ruel PROJECT MANAGEMENT: Rebecca Jones, Chris Gilloch, Sharon Wang SALES: Mike Brunke, Ruby Han, Maki Ishikawa, Stella Yan ART DIRECTOR: Kelly Buckheit Krause PUBLISHING: Nick Campbell, Richard Hughes, David Swinbanks

NATURE INDEX 2017 SCIENCE CITIES Nature Index 2017 Science Cities, a supplement to Nature, is produced by Nature Research, the flagship science portfolio of Springer Nature. This publication is based on data from the Nature Index, a Nature Research website maintained and made freely available at natureindex.com

NATURE EDITORIAL OFFICES

The Campus, 4 Crinan Street, London N1 9XW, UK

Tel: $+44(0) 2078334000$

Fax: +44 (0)20 7843 4596/7

\section{CUSTOMER SERVICES}

To advertise with the

Nature Index, please visit natureindex com/client-services feedback@nature.com

Copyright (๑) 2017 Macmillan

Publishers Limited, part of Springer Nature. All rights reserved. 